\title{
El libro como dispositivo representado y escrito
}

The book as a represented and written device

\author{
DIEGO ROLDÁN MARTÍNEZ MÉNDEZ* \\ Universidad Autónoma de Ciudad Juárez (UACJ) \\ México
}

*diego.martinez@uacj.mx

(iD) https://orcid.org/0000-0002-2461-9196

doi) https://doi.org/10.52948/ds.v3i2.423

Artículo de investigación

Recepción: 20 de noviembre de 2020

Aprobación: 1 de julio de 2021

Cómo citar este artículo:

Martínez Méndez, D. (2021). El libro como dispositivo representado y escrito.

Designio, 3(2), 163-183.

Reconocimiento-SinObraDerivada 4.0 Internacional (CC BY-NC-ND) 


\section{4}

\section{Resumen}

Al pensar sobre los usos y prácticas del libro a lo largo del tiempo, proponemos reflexionar sobre un planteamiento teórico: qué lo convierte en un dispositivo y un artefacto cultural; cómo esto se circunscribe a la palabra y la metáfora, transcurriendo por sus cualidades de representación, sus posibilidades conceptuales y simbólicas, así como su función como parte nodal de nuestra cultura. El libro como un símbolo y código de comunicación abierta permite observar el uso de métodos particulares de representación, alternos a sus usos tradicionales. El dilema se centra en encontrar una respuesta a los cuestionamientos del libro en la modernidad. Planteamos una revisión de conceptos y analogías para resolver y visualizar este propósito. Mostramos finalmente los medios conceptuales que hacen posible la compresión del libro como pináculo de la historia del ser humano.

Palabras clave: libro; dispositivo; artefacto cultural; símbolo; palabra; representación; metáfora.

\section{Abstract}

When thinking about the uses and practices of the book over time, we propose to reflect on a theoretical approach: what makes it a device and a cultural artifact, how this is limited to the word and the metaphor, passing through its representational qualities, its conceptual and symbolic possibilities, and its function as a nodal part of our culture. The book as a symbol and code of an open communication allows observing the particular use of methods of representation, alternative to its traditional uses. The dilemma centers on finding an answer to the book's questions in modernity. We propose a review of concepts and analogies to solve and visualize this purpose. We finally show the conceptual means that make possible the understanding of the book as the pinnacle of the history of the human being.

Keywords: book; device; cultural artifact; symbol; word; representation; metaphor. 


\section{Introducción}

Hay que considerar que al contemplar al libro en su concepción habitual, como una forma de representación del mundo y entendiéndolo como un relato de este; observando además los condicionamientos que se le han impuesto desde la antigüedad y muchos que aún persisten; podemos comenzar a comprender por qué han surgido, en paralelo a estas formas tradicionales de definirlo y los métodos claros del diseño editorial para materializarlo, otras maneras para su tratamiento y análisis; formas alternativas de representación y modos de contar la historia y darle lectura al mundo desde otro ángulo por medio de él. Hay que agregar que, entendido un como símbolo de consciencia, entrama infinidad de supuestos, lo que permite su utilización como medio para enfoques eclécticos y pragmáticos de la realidad del mundo. Tan simple o abstracto como esto puede sonar, lo anterior depende entonces de sus usos, su masificación y deconstrucción que van desde la voz del escritor, del historiador, del artista, desde la mirada del filósofo, del arquitecto, del editor o del diseñador; entendiendo así su universo complejo y las inagotables prácticas de hibridación que supone.

Dadas las circunstancias y maneras versátiles de abordarlo, se debe asumir que bajo estas posibilidades complejas de creación en cualquier dirección, a lo largo del análisis implicará un proceso de reflexión. Por un lado, los supuestos de concreción se verán amoldados por las ideas de algunos autores que son fuente fundamental de apoyo; por otro lado, la decantación que el mismo espíritu del proyecto origine. Por esto, una de las razones para poner en crisis al libro es evidenciar sus capacidades para someterse a la interrogante: ¿hasta qué punto resulta posible representar por medio de él ideas y conceptos desde la complejidad de la teoría para hacerlos visibles?

De tal manera, la preocupación se centra en que nuestro objetivo sea reflexionar principalmente sobre qué es lo que lo convierte en un dispositivo y cómo esto se circunscribe a la palabra y la metáfora. Lo anterior, atendiendo sus cualidades de representación, sus posibilidades conceptuales y simbólicas, para entender con ello su función como parte nodal de nuestra cultura. Apegándonos a este propósito, la indagación recae sobre una pregunta aplicada a cada una de las aristas propuestas: ¿de qué manera es un libro capaz de conjugar y dar sentido a la realidad por medio de la representación? 
Primeramente, nuestro enfoque respecto a este soporte, obviando su forma enciclopédica, no pretende decir que el libro contiene y dispone la totalidad de la realidad del mundo; mucho menos se trata de hablar de un culto al libro. Así las cosas, y bajo tal juicio, no estamos hablando de este como objeto de conocimiento total, sino como medio de difusión creativa y posibilitador de ideas; un reflejo y asentamiento de aspectos trascendentales de la historia y el pensamiento. Por esto, planteamos la hipótesis según la cual dada la trascendencia e importancia del libro en la cultura, se contempla que sea factible poder utilizarlo como un medio de representación de fenómenos complejos, que logre mostrar ese horizonte de sentido de comprensión del mundo.

En ese sentido, vemos su definición habitual y la manera en que se han puesto en crisis sus conceptos y prácticas; es decir, su estudio como dispositivo capaz de representar y generar sentido más allá de ser únicamente un depósito de texto o lenguaje. Atendemos constantemente a indagar sobre sus definiciones más normativas, y de alguna manera consolidadas, para posteriormente entender su rol en aspectos preponderantes de la cultura. Consecuentemente, bajo este acercamiento al objeto habitual, sondeamos sobre su cualidad de fluir bajo una carga simbólica que logra dar una mirada metafórica del mundo, acercándonos con ello a algunas formas de representación. Es así que necesariamente para este estudio debe existir un análisis transversal, a consecuencia del fenómeno del libro como sujetador temático y como modelo de representación. Por lo tanto, el análisis se ve guiado desde las problemáticas teóricas que supone dar respuesta a la noción de libro.

\section{¿Qué es un libro?}

Desde que el ser humano ha sido capaz de contar su historia, ha existido la necesidad de plasmar intereses, conocimientos y acciones realizadas en el mundo. Uno de los medios de representación, al que podemos observar como depósito formal de esta información, es el libro; desde sus primitivas confecciones hasta el objeto actual, incluyendo sus derivados e innumerables cuestionamientos acerca de su existencia y porvenir. Considerando al libro como un asentamiento de ideas de la humanidad, podemos pensar en la flexibilidad de sus usos para vaciar y mirar el contenido de nuestros pensamientos y preguntas; desde las formas tradicionales por medio de la escritura y el lenguaje, hasta maneras disruptivas enmarcadas en el diseño, el arte y la poesía. Por lo tanto, es este un objeto de interés en varios aspectos: su uso como 
dispositivo, su función como artefacto cultural, sus características metafóricas y sus cualidades de representación.

En principio, se debe contemplar que en la naturaleza del libro está ser polivalente, tener definiciones en varios sentidos y enfoques creativos diversos, por consiguiente, se encuentra siempre en etapa evolutiva. Decimos con esto que el libro apela al cambio y la adaptación, y es la razón por la que mayor audiencia está interactuando con él, como el lector pasivo y contemplador, o el creador más determinado en la tarea de mostrar nuevos horizontes de acción; no por nada, no ha sucumbido a los supuestos embates tecnológicos. Es necesario tomar en cuenta que tratar de conmensurar de manera visible alguna de sus dimensiones, sea esta filosófica, proyectual, retórica, editorial, plástica, etc., será parte del proceso iterativo que plantea esta reflexión. Debemos acotar también que el libro tiene algunas denominaciones hechas a lo largo de la historia, de las cuales aquí aparecerán las que aún hacen eco en el presente y también las que, por alguna razón, han sido relegadas o puestas en juicio por ser consideradas arcaicas, todo de acuerdo con la relevancia que sus autores puedan imprimirle.

El libro no es autocontenible, resumible o autoexplicativo, es decir, en su naturaleza está desdoblarse y ubicarse siempre en un horizonte de sentido. No se termina con dar vuelta a la última página, ya que si nos ceñimos a la analogía de verle como una representación del mundo, este, como el nuevo día, siempre tendrá otra página. Terminar de explorar un libro abre la puerta a la exploración de uno más, sea en forma seriada, en continuación, en reversa, o de manera aleatoria. Crear un libro abre el camino a imaginar uno nuevo, la exploración de este y/o el análisis de su predecesor. Los grandes libros sagrados despliegan la dimensión para explorar el ser y la consciencia, pero igualmente, llevan a otro lugar.

Vemos entonces al libro como un vehículo de comprensión de ciertos fenómenos de la realidad, segmentos de interés a los que el individuo intenta acceder por medio de él. En estos términos, sería tarea difícil proponer que se puede contener todo el conocimiento del mundo, como en su momento lo planteó Stéphane Mallarmé, sin llegar a cumplir con su intención, pero dejándonos con poemas en alusión a ello de manera metafórica, como "Un coup de dés jamais n'abolira le hasard" creado en 1897. Allí nos plantea el mundo simbólico como una posibilidad de comprensión (o no) del mundo, es decir, la manera de dar lectura (quizá sin sentido) para generar con ello una comprensión propia, o como hizo también Julio Cortázar con Rayuela de 1963, potenciando lecturas múltiples y variados sentidos de comprensión, misma acción que 
hacemos consciente únicamente al desdoblar las lecturas. Es por ello un buen modo de plasmar y esclarecer inquietudes pequeña o ampliamente complejas, porque más allá de su valor simbólico gozan de ser una herramienta al servicio de las ideas del ser humano.

\section{Forma simbólica del libro.}

En palabras de Melot (2008): "La forma del libro es, sobre todo, una forma simbólica en el sentido que le da E. Panofsky en La perspective comme forme symbolique [...], es decir, una forma que expresa, implícitamente, un conjunto de valores y representaciones del mundo" (p. 132). La regularidad de uso adquirida por el códice, y su dominio mucho antes de la imprenta, nos planta frente al cuestionamiento de dónde radica realmente la forma simbólica del libro. Michel Melot lo observa desde los textos sagrados y bíblicos, al argumentar que posiblemente las características anatómicas que vuelven práctico un códice permitieron que con el tiempo se adaptara mejor al uso cotidiano y continuo que exigía la Sagrada Escritura. Como resultado, en el transcurso del siglo I al IV, al tiempo que se consolidaba como el libro inherente y referencia para el cristianismo; su anatomía y disposición como soporte permitió al iletrado penetrar en el mundo de la escritura, y de cierta manera, integrarse a un universo al que antes no se le era permitido llegar, hasta incluso redactar sus propios pensamientos como testigo viviente de esa sacralidad. Al haber un orden práctico en el códice, en un sistema legible para el objeto que propició una mayor interacción, las dinámicas cambiaron, así como la disposición de jerarquías, por lo que el lector fue capaz de vivir una experiencia distinta. A destacar de la escritura, Melot (2008) señala:

La escritura es solidaria de su soporte, al que puede incorporarse prácticamente, el códice, lo que es más importante, se abrey se cierra. Es un objeto completo e independiente. Se puede decir que es autosuficiente. Contiene una verdad acabada cuya jerarquía interna puede organizarse de manera definitiva y estable con respecto a un conjunto finito. (p. 135)

Es quizá el sentido de estabilidad lo que facilita que el soporte adquiera una nueva dimensión no solo como un contenedor modelo de aquel tiempo, sino como fuente de confianza, basado en un simbolismo que habla de algunas inquietudes reflejadas en conceptos inciertos del ser humano, con base en la dualidad de la libertad y del 
espacio, como las de (dis)poner, explorar, abrir, terminar, dejar y en(cerrar). En este sentido, nos referimos a que la metáfora de estas disposiciones sobre el abierto y cerrado se materializa en la interacción con el códice, y aún más, al poseer la cualidad de "portabilidad" (Melot, 2008, p. 135). No hay razón entonces para no haber querido perpetuar estas bondades mediante el soporte que, al mismo tiempo, se llenó de carácter simbólico. Al observarlo como un espacio estructurado y notar la característica de ser proclive a generar un estímulo táctil o visual, el objeto como tal puede además generar asociaciones, experiencias, reminiscencias, etc., convirtiéndose entonces en material cognoscitivo.

Seguimos hablando del libro tradicional, el códice, que hasta la fecha ha hinchado las vitrinas por medio del texto en la página, contenido literario estructurado y esquematizado para seguirse produciendo y sustentando por muchos años más. De ahí que hablar de su sistematizada anatomía y secuencia editorial nos haga referirnos a él como una forma simbólica y llamarlo únicamente como libro, para referir toda la práctica tanto literaria, editorial y de mercadotecnia.

\section{El libro como dispositivo.}

Para que el libro se constituya como un dispositivo, debemos ver que, como hemos dicho anteriormente, es en sí mismo una estructura que genera simbolismos desde las palabras y su cualidad de objeto. A partir de ello se pueden integrar otras nociones que lo llevan a yuxtaponer diversas maneras de conjugación que permitan generar sentido, por lo que el dispositivo sería una trama compleja, factible de ser deconstruido y analizado; es una relación simbiótica entre variantes que desde la superficie no parecerían ser conexas, pero que al final convergen para conformarse como una estrategia (Agamben, 2015, pp. 10-11). Es, según lo plantea Foucault (1968), "tanto lo dicho como lo no dicho, he ahí los elementos del dispositivo" (p. 10), pues ya vemos que además hace sentido con el inicio de Las palabras y las cosas cuando menciona que la idea de Borges de hablar de una taxonomía tan inverosímil tiene que ver más con la imposibilidad y los límites del pensamiento, a los que normalmente no acudimos (p. 1). Así, vemos que Agamben retoma este principio y esencia, lo cual nos permite ver cómo en cierta manera tiene una conexión directa con el libro: carga con un trasfondo estratégico, se compone bajo un sentido estructural que, desde la antigüedad, ha traído consigo o se la ha otorgado la cualidad de dispositivo de poder 
y de conocimiento. Es decir, que el libro nunca carece de intenciones. En sentido más estricto, la palabra se compone de puras intenciones, su soporte las agudiza y les otorga la idea de vecindad.

Bien, si tomamos el libro como dispositivo en este sentido, antes hablábamos únicamente desde el lenguaje y la escritura, posteriormente con la imagen y el juego visual de caracteres, hasta que logra transgredir la tradición de la forma. Visto de esta manera, esto puede interpretarse como nuevos agregados al libro para conformarse, de manera sólida y tangible, como un dispositivo que puede dialogar sobre el poder y el saber. También cabe hacer la distinción nuevamente de que este lugar común no carece de intenciones; todo lo contrario, contiene el pensamiento de época tras época siendo parte del reflejo de la humanidad. Entonces, zal levantarse bajo el statu quo nos construimos como un dispositivo? Lo que se pretende con este cuestionamiento es dejar ver un poco las intenciones del dispositivo y la manera en que podemos extrapolar el concepto al libro. Las explicaciones de Agamben en torno a este juego de poder que plantea Foucault nos llevan a permanecer en el libro como un discurso de estrategia. Se podría decir que las intenciones de los artistas de retomar al libro en el siglo XX como un espacio disruptivo surgen a la par de dar una contra respuesta a los discursos hegemónicos.

Hay que ver también que el dispositivo "no se trata de un término particular que se refiere a esta o aquella tecnología de poder" (Agamben, 2015. p. 15); es una red con particularidades y generalidades, abstracto pero congruente, para contextualizar un objeto como el libro; al mismo tiempo es una decisión, un mecanismo y un plan (pp. 16-17). Ahora bien, Agamben (2015) nos propone la explicación de dispositivo, a lo que quizá podamos ceñirnos en mayor grado al concepto de libro, dada la amplitud:

Llamaré dispositivo literalmente a cualquier cosa que de algún modo tenga la capacidad de capturar, orientar, determinar, interceptar, modelar, controlar y asegurar los gestos, las conductas, las opiniones y los discursos de los seres vivientes. Por lo tanto, no solo las prisiones, los manicomios, el Panóptico, las escuelas, la confesión, las fábricas, las disciplinas, las medidas jurídicas, etc., cuya conexión con el poder de algún modo es evidente, sino también la pluma, la escritura, la literatura, la filosofía, la agricultura, el cigarrillo, la navegación, los ordenadores, los teléfonos móviles y -por qué no- el lenguaje mismo, que quizás es el más antiguo de los dispositivos, en el que miles y miles de años atrás un primate -probablemente sin darse cuenta de las consecuencias a las que se exponía- tuvo la inconsciencia de dejarse capturar. (pp. 23-24) 
Desde esta perspectiva, nuestra relación y convivencia con el dispositivo es inseparable; aún en aislamiento el lenguaje está presente en el pensamiento, digamos, como dispositivo interno. El propósito no es entonces cuestionar qué es un dispositivo, sino observar cómo un objeto como el libro se interpreta ahora en una esfera más amplia, capaz de conmensurar varias de sus posibilidades en un mismo espacio. Así, tratar al libro como un depósito, tanto en idea como en materia, nos lleva al dispositivo. De ahí que nuestra idea de libro como dispositivo desprenda la sensación de trazar un análisis transversal no solo que permita ver estos elementos regulatorios, sino que en poco o mayor sentido aporte a describir un objeto capaz de plantear estas interrogantes y, aún más, a desarrollar un discurso en torno a las características y posibilidades del libro para contener una estrategia que dé cuerpo a un planteamiento crítico.

\section{Artefacto cultural.}

El artefacto es una disposición del mundo de las ideas al mundo físico, traer al plano material un objeto elaborado bajo una técnica y rigor específicos, y que podemos denominarlo obra al sumar el arte o una cualidad artística en el proceso de elaboración. Sin embargo, el denominar artefacto al objeto conlleva a especificar que no son precisamente sinónimos; por el contrario, la idea o intangibilidad que permea a un objeto le otorga cualidades que lo replantean dentro de las "cosas".

Por un lado, existe el objeto en apariencia y utilidad, rasgos que al perderse o avejentarse lo sitúan dentro del mundo de lo utilitario de uso y deshecho; es un artefacto que no cobra sentido, sino que lo pierde. Por el otro lado, el artefacto cultural se da en función de una esencia y un funcionamiento o proceder. Según plantea Heidegger, hay una dimensión operativa en el objeto, es decir, "la cultura con sus innumerables presupuestos, convenciones y concepciones" (Isava, 2009, pp. 445446), dicho propiamente en términos del autor, "ponerse en obra". Aquí estaríamos viendo entonces la utilidad y la instrumentalización, sin agotar su sentido de existencia; podemos verlo acudiendo a Isava:

[...] en el artefacto cultural la materialidad se vuelve subsidiaria de su "poner en obra" la cultura. Esto nos permite afirmar (gloso aquí y reformulo un pasaje del texto de Heidegger): lo material en el artefacto cultural no puede negarse; pero en éste lo material debe pensarse a partir de lo que en él se pone en obra -lo que en él opera y se patentiza: la cultura. (p. 446) 
Por tanto, es generar una manera distinta de realidad a esa materialidad. Allí podemos plantear nuevamente, después y en torno del dispositivo, la aproximación de libro como artefacto cultural. En un primer sentido, hablamos del libro como un depósito y reflejo de conocimiento, por lo tanto, un entramado de convergencias a utilizar bajo un propósito específico. Después lo vemos como materialización de ese entramado, con la intención de distenderse no con un fin utilitario, no en base a la familiaridad queya conocemos, no como un recurso más para amplificar la cultura, sino como un momento esquematizado bajo las cualidades del libro para nombrar otros lugares, establecer otros intentos de expresión o describir otras interacciones que la misma cultura reconocerá bajo la forma de signo y bajo sus propios conocimientos sobre las representaciones. Particularmente, esto otorga dos virtudes al libro como artefacto cultural: una es el aprovechamiento de los factores tangiblesyya conocidos de su versión utilitaria, es decir, al ejecutar ciertas manifestaciones estéticas reconocibles en él, puede seguir orbitando próximo a su lectura y comprensión tradicional. La otra virtud, por tanto, es lo factible de capturar y exponer de otro modo, al desplazarse más allá de la forma, sin dejar su constante: la materialidad.

Por consiguiente, el libro como artefacto cultural '"pone en funcionamiento' las redes de significación que lo hacen posible y lo justifican, pero al mismo tiempo las patentiza al escenificarlas en una suerte de inscripción significante susceptible de ser leída, analizada, interpretada, (re)pensada" (Isava, 2009, p. 448). Así, el entramado del dispositivo y las redes del artefacto otorgan otras virtudes dentro del escenario tradicional del libro. Ya sea analizado desde su carácter de signo o su condición de aglutinador de conceptos, nos permite que el dispositivo se encargue de realizar la trama de lo que un libro puede llegar a ser. Asimismo, que imbrique a través de sus múltiples capas, un sentido y una intención de ser algo. Por tanto, que se comprenda como artefacto cultural que otorga vida al dispositivo y le da cabida en el imaginario colectivo de las representaciones.

\section{La palabra es al libro como el libro a la palabra}

Después de tratar al libro bajo su concepto de códice¹, o hablar de sus formas tradicionales, planteamos la palabra como el sistema que lo origina todo. Sin embargo,

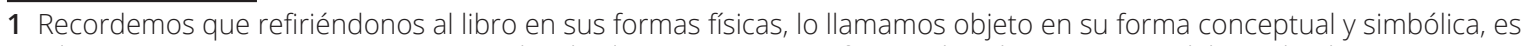
un dispositivo, y en sus usos intencionados, lo denominamos artefacto cultural, ya que en palabras de algunos autores, esto puede tomarse como sinónimo, por lo que hacemos la aclaración al final de algunas denominaciones. 
de la misma forma redondea el concepto, además de transgredirlo en su forma, como podría ser el caso de la poesía. Podríamos plantear que su detonante es la palabra, misma que desencadena posteriormente en el lenguaje, la escritura y en la tablilla. Entonces, la proliferación del lenguaje es lo que se materializa en el objeto. Aunque no pretendemos comprender el origen de la palabra, su desarrollo como lenguaje, o cómo se rige el ser humano por este código verbal; sí intentaremos buscar dónde gravita la conexión y adherencia entre esta y el libro. Comprender la relación desde una "arqueología" más que desde una historia como plantea Foucault (1968), es decir, donde los conocimientos "fuera de cualquier criterio que se refiera a su valor racional o a sus formas objetivas, hunden su positividad y manifiestan así una historia que no es la de su perfección creciente, sino la de sus condiciones de posibilidad" (p. 7).

Sobre la palabra habría mucho que decir en cuanto a su origen, pero lo que aquí pretendemos inferir sobre ella es su uso para representar el mundo; resulta en comprender parte de su sentido como código contextual y su manejo potencial e intencionalmente metafórico, redundando en su estructura visual. Foucault lo ve como una manera en la que el mundo se repliega sobre sí mismo; al referirnos a la palabra, deducimos -tal como él lo aprecia- un mundo complejamente signado, marcado o grafiado por la palabra. Es la manera de conocerlo, representarlo y replegarlo. Se entendería entonces desde su perspectiva:

El rostro del mundo está cubierto de blasones, de caracteres, de cifras, de palabras oscuras — de "jeroglíficos", según decía Turner. Y el espacio de las semejanzas inmediatas se convierte en un gran libro abierto; está plagado de grafismos; todo a lo largo de la página se ven figuras extrañas que se entrecruzan y, a veces, se repiten. Lo único que hay que hacer es descifrarlas: “¿No es verdad, acaso, que todas las hierbas, plantas, árboles y demás que provienen de las entrañas de la tierra son otros tantos libros y signos mágicos?". (Foucault, 1968, p. 35)

En este sentido, Octavio Paz miraba poéticamente al hombre como hijo de la palabra, pero también como su creador, afirmando que sin ella no seríamos hombres. A esto correspondería entonces considerar de manera breve ¿cómo se nombró al mundo?; si este gesto de nombramientos es consecuencia natural del pensamiento, entonces cómo se define exactamente qué cosa. Quizá como menciona Foucault, por 
la vecindad de ubicación de las cosas en cuanto a proximidad, forma o función; por analogías que se van replegando una con otra constantemente entre sí.

Por su parte, McLuhan (1996) señala este aglutinamiento de palabras, es decir, el lenguaje "como extensión o emisión (exteriorización) de todos los sentidos, el lenguaje siempre se ha considerado la más rica forma de arte del hombre, la que lo distingue del mundo animal" (p. 97). Pone entonces en discusión la palabra escrita y la fonética; basado en Henri Bergson (1984), McLuhan (1996) nos dice: "el lenguaje es una tecnología humana que ha impedido y disminuido los valores del inconsciente colectivo" (p. 97). Sin embargo, es en su versión escrita donde ordena al mundo, donde permite ver y dejar por sentado en el tiempo lo sucedido pues su poder se refleja en que "deletrea secuencialmente lo que la palabra hablada tiene de rápido y de implícito" (p. 97); narra mientras dispone cronológicamente.

Es quizá entonces que la escritura en forma de signos visuales toma más sentido en el lenguaje ya que lo enriquece. A su vez, estos signos visuales designan y nombran el mundo; también nos revelan la capacidad integrada en las palabras para abrir la periferia de significados que Foucault ubica como fenómeno del siglo XVI, como un uso por similitud. Es decir, el carácter metafórico del lenguaje lo propone como algo en movimiento y es precisamente esta característica la que lo vuelve difícil de definir; lo deja abierto entonces a la interpretación. Podríamos decir que girar sobre interpretaciones es su naturaleza.

[...] el lenguaje no es un sistema arbitrario; está depositado en el mundo y forma, a la vez, parte de él, porque las cosas mismas ocultan y manifiestan su enigma como un lenguaje y porque las palabras se proponen a los hombres como cosas que hay que descifrar. La gran metáfora del libro que se abre, que se deletrea y que se lee para conocer la naturaleza, no es sino el envés visible de otra transferencia, mucho más profunda, que obliga al lenguaje a residir al lado del mundo, entre las plantas, las hierbas, las piedras y los animales. (Foucault, 1968, pp. 42-43)

Esta analogía con la arqueología de Foucault nos lleva a plantear el problema por el lado de lo que algo no es, o donde no queremos que se encierre. Debido a esta característica, notamos en el texto escrito el primer paso hacia el libro, un soporte para contener diversas formas al lenguaje, de expresarlo diferente, pues no es meramente un contenedor cerrado de aquél. Debemos verlo como un espacio para extender su significado mediante otros usos y condiciones. En palabras de Ulises Carrión (2016), lo 
que se afirma es que "el libro no es un estuche de palabras, un saco de palabras, un soporte de palabras" (p. 37); quizá es un proceso iterativo para el lenguaje, es lo que McLuhan (1996) cita sobre un estante de libros: "poco a poco, llegué a comprender que los signos en las páginas eran palabras atrapadas. Cualquiera podía aprender a descifrar los símbolos para volver a liberarlos en forma de habla" (p. 99); lo retoma como extensiones o prolongaciones del ser humano, en este caso una extensión/ interpretación del lenguaje -y recordando su cualidad de movimiento- que a su vez flexibilizará posteriormente al libro en todas sus características. No únicamente los libros, sino los objetos artificiales los podremos ver entonces -retoma McLuhan de Hall- para el hombre como.

[...] extensiones o prolongaciones para realizar casi todos los actos que antes llevaba a cabo solo con su cuerpo. La evolución de las armas comienza en los dientes y el puño y termina en la bomba atómica. [...] Las máquinasherramienta, las lentes, la televisión, los teléfonos y los libros, que transmiten la voz a través del tiempo y del espacio, son ejemplo de extensiones materiales. [...] De hecho, todas las cosas materiales realizadas por el hombre pueden considerarse como extensiones de lo que el hombre hizo antes con su cuerpo o con alguna parte especial de él. (Hall, 1959, p. 79, como se citó en McLuhan, 1985, p. 5)

Por lo tanto, bajo esta noción estaríamos haciendo entonces alusión al desarrollo de un dispositivo de comunicación con la "palabra"; un conjunto de caracteres que se han dispuesto y utilizado para generar así la maquinaria tan compleja que es el lenguaje. Si bien el lenguaje se puede trasformar y estirar para ciertos fines, es una parte de los engranajes y herramientas que vuelven al libro un dispositivo de conexión entre intenciones y fines, es decir, no puede existir en primera instancia, el libro sin la palabra. Sin embargo, ahora podemos considerar uno sin el otro, por ser medios de representación conexos más no inseparables.

Posterior a la invención de la imprenta de Gutenberg, se consideró como premisa de este pasado que no podía existir esta tecnología sin la escritura, por lo tanto, no se podía concebir uno ni otro sin el uso de la palabra. El avance tecnológico reflejado en esta máquina extendió considerablemente los brazos del ser humano para abarcar en mayor medida el horizonte del pensamiento vertido en este conocido y renovado objeto, ahora más público y con gran capacidad de reproducción: el libro impreso. 
Entendemos que la imprenta fue un gran avance para la cultura, como un nuevo "fuego" o una nueva "rueda" y, al igual que entonces, hemos visto que "toda tecnología tiende a crear un nuevo mundo circundante para el hombre. La escritura y el papiro crearon el medio ambiente social de los imperios del mundo antiguo" (McLuhan, 1985, p. 2). Por ello, también el progreso implica siempre un cambio, si no radical, sí considerable del estado de las cosas. Este cambio, a diferencia del mundo antiguo, fomentaría lo posteriormente conocido como enciclopedismo. Ortega y Gasset (2005) subraya la significación de la llegada de la imprenta y el impacto en el hombre. Si consideramos que en el reino animal todo ser comienza de cero, con el suceso del libro impreso el ser humano comienza a "heredar formas de existencia"; parte de una acumulación paulatina de conocimientos, poniéndose en contacto con las vidas pasadas por medio del artefacto del libro o, como él lo llama, "instrumento" (p. 62).

Esentoncestraslallegada deeste"instrumento"(objeto), producto dela acumulación de años de conocimientos y experimentación, que veríamos las consecuencias prácticas y significativas de lo que ya no solamente requeriría de un conocimiento puramente empírico porque para plasmar el escrito, antes que la máquina está el saber expresar con la palabra y narrar el mundo a través de la letra; la variedad de habilidades que implicaba llevar el pensamiento al impreso se constituiría como un saber hacer. Gutenberg sería lo equiparable a la acción reiterada del saber hacer como "acción ejecutada por un agente profesional que pone en operación las habilidades teórico-prácticas en contextos útiles" (Mosqueda, 2017, pp. 18-19).

Este contexto sobre el saber hacer constituiría a la imprenta como una práctica elaborada. Retomando entonces a Mosqueda, quien nos indica: "una práctica puede notarse como el mediador de un 'entramado' de compromisos, modelos, habilidades, instrumentos, discursos, lenguajes, estilos, materiales estandarizados y fenómenos hechos por la acción de los agentes de un saber" (p. 17); explica que dicho conocimiento exteriorizado como libro impreso, conformará entonces un nuevo modelo de expresión. La corporalidad del pensamiento es integrada ahora al tiempo que se presenta como una forma singular de la palabra, "esa exteriorización o expresión de ideas y sentimientos que es el lenguaje y el hablar, es un instrumento que 'hizo posible al hombre la acumulación de experiencia y conocimientos, y facilitó su transmisión y máximo empleo posible"' (White, 1957, p. 240, como se citó en McLuhan, 1985, p. 5), ahora palpable como formato de libro.

En estas "formas de existencia", como menciona Ortega y Gasset (2005), "los libros

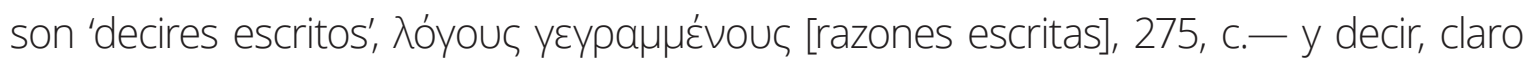


está, no es sino una de las cosas que el hombre hace. Ahora bien, todo lo que se hace, se hace para algo y por algo" (p. 86), y poder decir en que se ha convertido este saber hacer quizá lo podamos encontrar mejor continuando con la arqueología del libro. Después de todo, menciona Borsuk (2018):

[...] es un método portátil de almacenamiento y distribución de datos, y surge como un subproducto del cambio de la cultura oral a la alfabetizada, un proceso que lleva siglos y se informa a través del intercambio cultural, tanto pacífico como forzado. En el desarrollo del libro desde la tableta de arcilla hasta el códice, las posibilidades de cada medio -las posibilidades de uso presentadas por su forma- facilitan ciertos tipos de expresión. (p. 1)

Cada fase de la creación en el libro nos permite entonces ir reflexionando de manera consciente sobre cómo podemos llegar a la confección de un dispositivo para convertirlo en un artefacto cultural, mediante la palabra y sus usos simbólicos.

\section{La metáfora en el libro.}

Por sus cualidades metafóricas el libro funcionará para representar realidades, por ende, también para crear las propias, para desarrollar paralelismos que no confinan a una verdad esencial o única, sino que desencadenan propuestas y probabilidades de ver el mundo. En este sentido, Mallarmé apelaba por desvelar la verdad total con Le livre, pero gracias a ello es que podemos entender que el libro no es concluyente o un espacio ideológico finito. Mejor, es una idea con el poder de contextualizar realidades y/o ficciones de modos múltiples para comprender lo que no es visible, donde la metáfora es funcional en el juego de poder representar A por medio de B según lo menciona una fórmula básica.

Lo que vemos por ejemplo en algunos escritos como El libro de arena de Jorge Luis Borges (2003), donde se narra: "su libro se llamaba El libro de arena, porque ni el libro ni la arena tienen principio ni fin" (p. 176); alude a la metáfora: una manera de ver el libro como un dispositivo de apertura al mundo, un lugar sin límites y sin bordes, sin un principio ni un fin, que nos remite a la idea del espacio infinito dentro de él. Si físicamente dicha idea es imposible, el relato la hace posible mediante el contexto de las palabras, creando un espacio intangible pero posible a nivel de representación de las ideas. No solamente vemos que hay una cualidad desde la literatura para generar contexto, sino que es la metáfora la que apela a la posibilidad del crear espacios mentales. 
Por otro lado, Mannoni (1985) menciona que "la estructura no puede producir sentido. Trata de prescindir de él... al burlar lo simbólico" (p. 21). Nos habla entonces de una pérdida de sentido al querer estructurar el lenguaje; veía la posibilidad de exploración del lenguaje a partir de la visión poética de Mallarmé, quien mencionó con tono enigmático:

La poesía compensa la imperfección de las lenguas. [...] A la lingüística no le interesan [esas] cuestiones. Para ella las lenguas no tienen defectos, como tampoco los tienen los cuerpos simples para los químicos, ni los planetas para los astrónomos. (p. 17)

Lo que en este sentido se intenta expresar a partir de esta visión mallarmeana, es observar la consecuencia: por un lado, de ver las posibilidades del libro en cuanto a su estructura física como un constructor de sentido. Por el otro, evidenciar su contenido y en este sus posibilidades metafóricas, como una compensación de otros tipos de lenguaje, y también como un constructor de sentido, en su sentido de dispositivo. Entendemos que estamos hablando del lenguaje como una tecnología moldeable, al igual que la imprenta se constituyó como tecnología a favor de la fisicalidad del libro en pro de su reproducción. En ambos casos, su deconstrucción permite nuevas posibilidades creativas.

En este sentido, decimos entonces que el libro se conforma como un acercamiento y respaldo de modelos dialécticos, donde la importancia y esencia de ideas y conceptos, además de radicar en la interacción entre ellos, se basa en la manera de incorporarse y representarse en este continente. De esta manera, el libro es en esencia de cualidad metafórica, pues se presenta como un espacio capaz de (des)articular el pensamiento en busca de estrechar los puentes entre realidades aparentemente distintas, con el fin de no solo amalgamar un objeto físico, sino generar sentido y extender el diálogo bajo la premisa de dispositivo. Ya en un momento temprano podíamos apreciar que si bien el libro es una manera de abrir el diálogo siendo un contenedor del pensamiento, quizá no lo hacía de manera bilateral, pues únicamente el uso de un modelo interactivo permitió comprender las ideas en un sentido más amplio y enriquecer así la perspectiva y comprensión del lector. Bajo este modelo de apertura, la experiencia que brindará un libro, así como la propia experiencia del lector, pueden generar su propio sentido. Desde la metáfora este puede afectar "a las representaciones internas, [y] la visión del mundo que tiene el hablante" (Millán y Narotzky, 2009, p. 12). 
Por lo tanto, el uso de la metáfora para explicar una realidad específica es importante en el sentido de dotar de recursos, si no ilimitados, sí muy diversos a la representación. Entendemos también su importancia al absorber a un universo de conceptos abstractos y poder dar claridad y coherencia a estos, es decir, la metáfora alcanza a contextualizar los polos opuestos; brinda composición y armonía, destapa los lugares oscuros que a menudo entendemos como incoados y nos acerca un paso más a la comprensión. Sin embargo, con ello decimos claramente que no otorga el último componente de comprensión ni da la respuesta final al problema; en cambio, de manera alterna abre el camino hacia una comprensión que no se cierra.

Lo anterior es ocasionado pues en la mayor parte del uso de nuestro lenguaje de forma natural y común, disponemos de un sistema metafórico para comunicar; además, esto nos posibilita un mayor espectro de comprensión del mundo y podemos trazar de manera paralela una analogía con el universo de comprensión del libro. Es decir, indagando sobre la metáfora y sus componentes podemos tratar la composición y conceptos del libro; como hemos mencionado, existen relaciones naturales y dadas desde su origen de manera nativa respecto a cómo hemos venido interactuando con él como un objeto convencional, por lo que las metáforas en el uso del lenguaje son una forma más sólida de imbricar las piezas para el diálogo con el libro.

Según apreciamos en la perspectiva de LakoffyJohnson (2017), podemos plantear que si una metáfora forma parte esencial de la vida cotidiana del ser humano en la manera de pensar y expresarse, por ejemplo, si en un lenguaje tradicional hablamos de espacio o ubicación; estaremos utilizando las metáforas de orientación por lo general compuestas por opuestos como arriba/abajo. Seguidamente, si tratamos de explicar al libro como un objeto que sería el equivalente a hablar de los sustancial del ser humano, como una entidad, sustancia o contenedor; estaremos recurriendo a las metáforas ontológicas.

En el formato tradicional del libro, esto se traduce a su capacidad para incorporar, dar cuerpo y sentido a las ideas; también están las metáforas estructurales que permiten responder ¿qué es algo intangible en términos de representación?, por ejemplo, decir que "una lectura es un recorrido". Al final, son áreas básicas de la experiencia humana que se presentan de manera natural "en cuanto que provienen de campos de comprensión inmediata, ya sean físicos o culturales: nuestro cuerpo, nuestras interacciones con el entorno físico (movimiento, manipulación de objetos, etc.) y nuestras interacciones con otras personas en nuestra cultura (sociales, [...] etc.)" (Millán y Narotzky, 2009, p. 13). 

un libro como un recorrido, un pensamiento y un objeto, necesariamente estaremos tratando el tiempo y espacio, lo que nos permite atender lo siguiente:

El pensar es una sucesión de ideas en el tiempo, como el hablar es una sucesión de palabras. 'El tiempo es espacio' es una metáfora fundamental en muchas lenguas. En virtud de ella la sucesión temporal es sucesión espacial: las ideas, las palabras, o el conjunto de ambas, se mueven a lo largo de un trayecto, discurren por un camino, configurando un viaje. (Millán y Narotzky, 2009, p. 15)

Es así como esta fuente integral de comprensión del mundo, en el sentido físico y de orientación, nos permite acercarnos a lo que es un libro, pues si bien comenzamos diciendo que este es una extremidad del ser humano como lo vemos en McLuhan (1985); las referencias simbólicas se vuelven cada vez más constantes, dado que la metáfora tiende a diversificarse, a ir encontrando más caminos y distintos lugares donde posarse.

Como hemos dicho, no están hechas todas las metáforas. Como menciona Lakoff y Johnson (2017), estas van aconteciendo de acuerdo con una época y se determinan con base en los picos icónicos que reflejan y simbolizan a una cultura. Por ejemplo, el "hilo del discurso" o "hilar", que tendría que ver con la actividad textil en expansión de una época determinada, pasó a ser reemplazada por "el vehículo": una nueva manera de conectar elementos y crear contextos al entender esta nueva tecnología como un hito en aquel tiempo. Donde ahora las cosas se conectaban de un lugar a otro de manera más rápida, esta tecnología fue entonces el 'vehículo' para nuevas formas de metaforizar.

Entendemos que para que exista la metáfora debe haber un razonamiento cultural colectivo para dar rienda suelta a sus usos. Sin embargo, en una cultura donde el arraigo, costumbres y tradiciones mantienen el status quo, quizá no se perciban muchos cambios en cierto lapso de tiempo, en palabras de Lakoff y Johnson (2017) "las metáforas son básicamente culturales, y además en gran medida propias de cada lengua determinada" (p. 24), de ahí que se hable de metáforas fosilizadas. 


\section{Conclusiones}

El libro como dispositivo representado y escrito se plantea como un intento por establecer una mirada sobre la manera de cómo nos trazamos la realidad y cómo es que los sistemas de representación funcionan a partir de su tratamiento objetivo. La reflexión que aquí se propone alrededor del libro se aborda desde un pensamiento crítico. Podemos tenerlo en cuenta como una noción de pensamiento crítico y científico para comprender el mundo y la realidad, o al menos parte de ellos. Gaston Bachelard (2000) plantea el pensamiento científico como algo abstracto y nos habla de que las construcciones metafóricas son más recurrentes que las reales para explicar fenómenos. En analogía a esta postura, otra de las funciones del libro es descubrir si los escalones que hemos conseguido alcanzar, no solo en la ciencia, sino en la historia, nos han llevado hacia una postura más o menos lúcida sobre lo que creemos es el pilar de la humanidad: quitar un velo, si es que lo hay, contradecir la experiencia común y anteponer la experiencia científica para llegar a resolver los problemas de la representación de lo abstracto.

Totalizar es polarizar el pensamiento y encajonarlo. Tal como vemos la representación, nada es certero ni concreto, todo es insondable, por ende, los problemas correctamente planteados generan nuevas visiones y dinamizan el campo de la ciencia. Al descubrir las complicaciones vertebrales de los fenómenos se llega a abrir un abanico o campo de conocimiento más propositivo, por lo tanto, ciertos tipos de libros consisten entonces en evitar ciclarse y llegar a la autocomplacencia. Tratar de "dialectizar la experiencia" e "interrogar mejor", porque a fin de cuentas lo que nos proponemos no es cerrar el objeto, sino proponer maneras de canalizar mejor el conocimiento por medio de él, logrando llegar al dispositivo. En este aspecto no hablamos de una construcción metódica, sino de una reflexión consiente en sus formas de análisis y construcción, sea cual sea la vía por la cual intentemos llegar.

El libro contextualiza un espacio y un tiempo, los tallados sobre piedra y tablillas de culturas antiguas anticipaban ya un inagotable modo conceptual: el dispositivo. Se observa que en el pasado el intento inicial hacia la creación del objeto (posteriormente llamado libro) se gestó mediante una necesidad de expresión que se basaba en los soportes disponibles. Si apelamos a las constelaciones como ejemplo de la manera en dar lectura a ellas por civilizaciones antiguas, veremos que existe una forma natural de comprender el universo a partir de verlo como un gran soporte de elementos que comunican algo o que poseen la cualidad de mostrarnos algo que no sabemos, pero 
que, a partir de la observación y la lectura desde diversas perspectivas, nos darán información y contexto sobre el panorama. En el caso de las estrellas, vemos que existe una lectura generada por su movimiento y disposición sobre el cielo: un gran libro.

Quizá entonces, tanto el movimiento celeste como la compenetración del ser humano, con los objetos sobre tierra, tiene una inferencia en nosotros y la capacidad de representar y expresar sobre distintos soportes naturales y artificiales. Es decir, habría una manera arraigada de leer y expresar el mundo insertada en nosotros con una finalidad: representar en un soporte autocontenido, mediante cierta narración, una visión de la realidad. Esta manera deriva en el libro como espacio contextualizador. La perspectiva que tenemos entonces hacia el libro radica en tomarlo como espacio de conocimiento, capaz de convertirse desde el tratamiento conceptual, en dispositivo y artefacto cultural, englobando con ello su capacidad de representación del mundo, como medio catártico para el creador, como símbolo de sabiduría con la capacidad de distenderse al espacio y tiempo. 


\section{Referencias}

Agamben, G. (2015). ¿Qué es un dispositivo? Anagrama.

Bachelard, G. (2000). La formación del espíritu científico. Contribución a un psicoanálisis del conocimiento objetivo. Siglo XXI editores.

Borges, J.L. (2003). El libro de arena. Grupo Editorial Planeta.

Borsuk, A. (2018). The Book. MIT Press.

Carrión, U. (2016). El arte nuevo de hacer libros. Tumbona Ediciones.

Isava, L. (2009). Breve introducción a los artefactos culturales. Estudios. Revista de investigaciones literarias y culturales, 17(34), 439-452.

Foucault, M. (1968). Las palabras y las cosas. Siglo XXI.

Lakoff, G. y Johnson, M. (2017). Metáforas de la vida cotidiana. Ediciones Cátedra.

Kristeva, J, Mannoni, O., Ortigues, E., Schneider, M. y Haag, G. (1985). El trabajo de la metáfora. Gedisa.

McLuhan, M. (1985). La galaxia de Gutenberg. Planeta.

(1996). Comprender los medios de comunicación: Las extensiones del ser humano. Paidós.

Melot, M. (2008). El libro como forma simbólica. Revista Venezolana de Información, Tecnología y Conocimiento, 5(3), 129-139.

Millán, J., y Narotzky, S. (2017). Introducción. En J. Lakoff y M. Johnson (Eds.), Metáforas de la vida cotidiana. (pp. 9-25). Ediciones Cátedra.

Mosqueda, C. (2017). Interpelaciones del arte, el diseño y la sociedad. Universidad Autónoma Metropolitana.

Ortega y Gasset, J. (2005). Misión del bibliotecario. Consejo Nacional para la Cultura y las Artes. 